\title{
Proteus Syndrome: Report of Intra-Abdominal Lipomatosis
}

\author{
Basak Erginel ${ }^{1} \quad$ Melih Akin $^{1} \quad$ Abdullah Yildiz $^{1}$ Cetin Karadag ${ }^{1}$ Nihat Sever ${ }^{1}$ Canan Tanik ${ }^{2}$ \\ Mehmet Erturk ${ }^{3}$ Ali Ihsan Dokucu ${ }^{1}$ \\ ${ }^{1}$ Department of Pediatric Surgery, Sisli Etfal Education and Research \\ Hospital, Istanbul-Sisli, Istanbul, Turkey \\ 2 Department of Pathology, Sisli Etfal Education and Research Hospital, \\ Istanbul-Sisli, Istanbul, Turkey \\ ${ }^{3}$ Department of Radiology, Sisli Etfal Education and Research Hospital, \\ Istanbul-Sisli, Istanbul, Turkey \\ Eur J Pediatr Surg Rep 2013;1:38-40. \\ Address for correspondence Basak Erginel, Department of Pediatric \\ Surgery, Sisli Etfal Educatıon and Research Hospital, Istanbul-Sisli, \\ Istanbul, Turkey (e-mail: basakerginel@hotmail.com).
}

\begin{abstract}
Keywords

- Proteus

- lipomatosis

- intra-abdominal

Proteus syndrome (PS) is an extremely rare sporadic disorder that manifests as an asymmetric, disproportionate overgrowth of any connective tissues, such as bone, fat, or epidermal nevi, in a mosaic or patchy pattern. This hamartoneoplastic syndrome was first described by Cohen and Hayden. Its prevalence is approximately 1 per 1,000,000 live births, and intra-abdominal expansion has been reported in no more than 20 cases in the literature. The phenotypes of the patients differ because of the variation in the pattern of the overgrowths, making diagnosis difficult. Extremely large subcutaneous lipomas and internal lipomas, which occur rarely, are one of the presentation phenotypes. Here, we present the second patient in the literature with PS involving the epiploon.
\end{abstract}

\section{Case Report}

A 5-year-old male patient was admitted with right abdominal swelling. He had underwent an operation for an enormous lipoma, approximately $20 \mathrm{~cm}$ in diameter, on his back in our clinic when he was 1.5 years old, and plastic surgery was performed following amputation for macrodactyly of his right first and second toes when he was 4 years old. During this time, he had no abdominal scanning. On physical examination, he had an abdominal mass almost $30 \mathrm{~cm}$ in diameter, a right lower extremity overgrowth, two amputated right foot fingers, and an incision scar on his back. Abdominal magnetic resonance imaging revealed a giant hypodense lesion, stretching from the inferior of the liver to the inguinal region covering the right kidney and the right ureter. The density of the masses were approximately $-100 \mathrm{HU}$, in accordance with lipid density, both lining intra- and extraperitoneally ( - Fig. 1). The mass had begun to impair his motor development and mobility. At laparotomy, a giant mass was found, surrounding all the abdominal organs, including the liver, kidney, ureter, mesocolon, colon, omentum, and intestines on the right side and extending to the inguinal canal. The lipomas were meticulously dissected from the surrounding organs and completely excised ( - Fig. 2). The postoperative period was uneventful. Liposuction was planned to remove the remainder of the adipose tissue in the right lower extremity. Pathological examination revealed a lipoma.

\section{Discussion}

Proteus syndrome (PS) is an extremely rare sporadic disorder that manifests as an asymmetric, disproportionate overgrowth of any connective tissues, such as bone, fat, or epidermal nevi, in a mosaic or patchy pattern. This hamartoneoplastic syndrome was first described by Cohen and Hayden. ${ }^{1}$ Its prevalence is approximately 1 per $1,000,000$ live births, and intra-abdominal expansion has been reported in no more than 20 cases in the literature. ${ }^{2}$ received

November 30, 2012

accepted after revision

January 30, 2013

published online

April 20, 2013 (c) 2013 Georg Thieme Verlag KG Stuttgart · New York
DOI http://dx.doi.org/ 10.1055/s-0033-1343078. ISSN 2194-7619. 


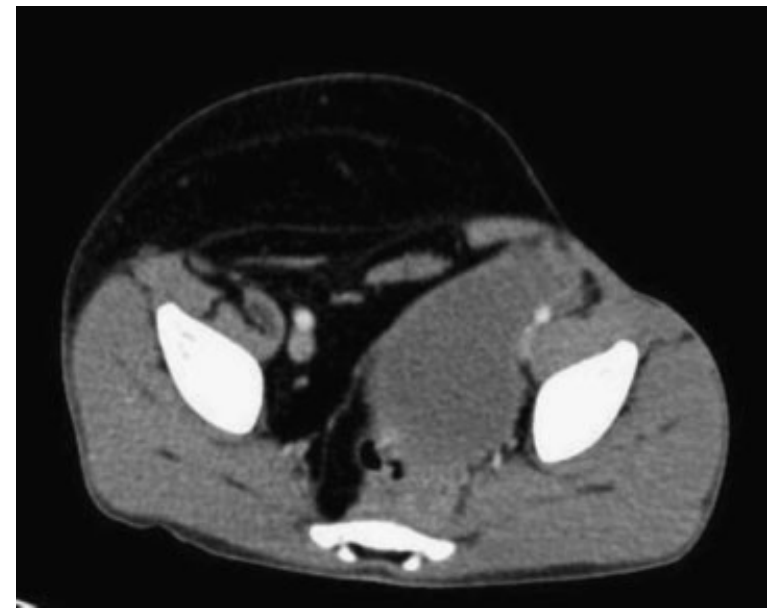

Fig. 1 Abdominal magnetic resonance imaging revealed a giant hypodense lesion, stretching from the inferior of the liver to the inguinal region covering the right kidney and the right ureter.

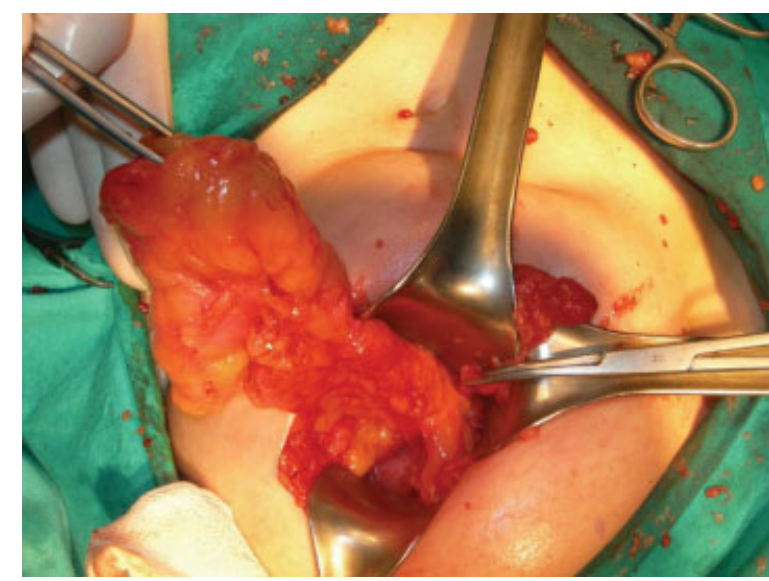

Fig. 2 Abdominal lipomatosis was meticulously dissected from the surrounding organs and completely excised.

Diagnosing PS is a challenge due to its different presentations and the overgrowth of different tissues and localizations. In 1999, Biesecker et al developed diagnostic criteria (-Table 1) and evaluation guidelines to clarify the diagnostic confusion. ${ }^{3}$ The coexistence of the syndrome with other manifestations such as scoliosis, central nervous system anomalies, and thoracic deformity anomalies has also been described. 4

Some overgrowth syndromes including PS, Klippel-Trenaunay syndrome, and hemi-hyperplasia-multiple lipomatosis syndrome have been delineated. Sapp et al defined a new overgrowth syndrome resembling PS named CLOVE (congenital lipomatous overgrowth, vascular malformation, epidermal nevus) syndrome. ${ }^{5}$ Our case differed from the CLOVE syndrome because there was no vascular malformation, epidermal nevi growth, or the presence of skeletal overgrowth.

Biesecker et al have been working in the field of overgrowth and presented recent diagnostic criteria for PS. ${ }^{6-8}$ Our case showed all the major diagnostic criteria of the syndrome, that is, mosaic distribution, a progressive course, and sporadic
Table 1 Proteus criteria

\begin{tabular}{|l|l|}
\hline \multicolumn{2}{|l|}{ Mandatory general criteria } \\
\hline $\begin{array}{l}\text { Mosaic distribution of lesions } \\
\text { Progressive course } \\
\text { Sporadic occurrence }\end{array}$ \\
\hline Specific criteria (1 from A, 2 from B, or 3 from C) \\
\hline B. & $\begin{array}{l}\text { 1. Connective tissue nevus } \\
\text { 1. Epidermal nevus } \\
\text { 2. Disproportionate overgrowth (one or more) } \\
\text { Limbs } \\
\text { Skull hyperostoses } \\
\text { Vertebrae megalospondylodysplasia } \\
\text { Viscera } \\
\text { 3. Specific tumors before the end of the } \\
\text { second decade (either one) } \\
\text { Parotid monomorphic adenoma } \\
\text { Bilateral ovarian cystadenomas }\end{array}$ \\
\hline $\begin{array}{l}\text { 3. Facial phenotype } \\
\text { Dolichocephaly } \\
\text { Long face } \\
\text { Minor downslanting of palpebral } \\
\text { fissures and/or minor ptosis } \\
\text { Low nasal bridge } \\
\text { Wide or anteverted nares } \\
\text { Open mouth at rest }\end{array}$ \\
$\begin{array}{l}\text { 1. Dysregulated adipose tissue (either one) } \\
\text { Lipomas } \\
\text { Regional absence of fat }\end{array}$ \\
\hline
\end{tabular}

Source: Adapted from Biesecker et al. ${ }^{3}$

occurrence. As in our case, lipomas in PS are composed principally of mature adipocytes, and the adipose tissue shows dysregulation. ${ }^{3}$

Our patient also had macrodystrophia lipomatosa, which is characterized by the enlargement of one or more fingers or toes with predominantly fibroadipose tissue. Macrodystrophia lipomatosa can be part of an overgrowth syndrome such as $\mathrm{PS},{ }^{8}$ as in our patient, or CLOVES syndrome, ${ }^{5}$ or it can be found as an isolated abnormality in an otherwise normal patient. 9,10

The syndrome is so rare that there are few case reports in the literature. In 2002, Lublin et $\mathrm{al}^{11}$ described three patients with PS and conducted a review of the literature regarding abdominal, otolaryngological, and thoracic manifestations and surgical complications. Their three patients with intraabdominal occurrence of the syndrome were treated conservatively. One of the patients, a male, required an emergent exploration for an acute abdomen secondary to a twisted necrotic portion of the right iliac. One of the other two patients with retroperitoneal PS was treated conservatively, 
and the other underwent an operation for extension to the inguinal canal, as in our case. ${ }^{11}$ The surgical approach to PS with intra-abdominal and retroperitoneal extension is primarily conservative, with surgery reserved for cases that are invasive in nature or where the pathology causes compressions or complications.

Any organ or tissue can be affected in PS; therefore, the secondary complications are highly variable. It is associated with a range of tumors, pulmonary complications, progressive skeletal deformities, invasive recurrent lipomas, and a striking predisposition to deep vein thrombosis and pulmonary embolism. ${ }^{12}$ For the last 1 year, our patient is under careful follow-up to detect local relapse with abdominal ultrasongraphy in every 6 months.

By presenting a case with PS, we aim to draw attention to the diagnosis, the treatment modalities, and the place of surgical intervention in this rare disorder. Despite their histological appearance, intra-abdominal lipomas increase the potential for invasiveness in patients with PS. Such patients must have a conservative follow-up, with periodic radiological imaging. Surgical intervention is indicated when the overgrowth causes physical compression of the surrounding organs, as in our case.

\section{Conflict of Interest}

None

\section{References}

1 Cohen MM Jr, Hayden PW. A newly recognized hamartomatous syndrome. Birth Defects Orig Artic Ser 1979;15(5B):291-296
2 Furquim I, Honjo R, Bae R, et al. Proteus syndrome: report of a case with recurrent abdominal lipomatosis. J Pediatr Surg 2009;44(4): E1-E3

3 Biesecker LG, Happle R, Mulliken JB, et al. Proteus syndrome: diagnostic criteria, differential diagnosis, and patient evaluation. Am J Med Genet 1999;84(5):389-395

4 Yamamoto A, Kikuchi Y, Yuzurihara M, Kubota M, O’uchi T. A case of Proteus syndrome with severe spinal canal stenosis, scoliosis, and thoracic deformity associated with tethered cord. Jpn J Radiol 2012;30(4):336-339

5 Sapp JC, Turner JT, van de Kamp JM, van Dijk FS, Lowry RB, Biesecker LG. Newly delineated syndrome of congenital lipomatous overgrowth, vascular malformations, and epidermal nevi (CLOVE syndrome) in seven patients. Am J Med Genet A 2007;143A(24):2944-2958

6 Biesecker LG, Rosenberg MJ, Vacha S, Turner JT, Cohen MM. PTEN mutations and proteus syndrome. Lancet 2001;358(9298): 2079-2080

7 Biesecker LG, Cohen MM Jr. Misdiagnosis of neurofibromatosis type 1 as Proteus syndrome. Panminerva Med 2005; 47(3):197

8 Biesecker L. The challenges of Proteus syndrome: diagnosis and management. Eur J Hum Genet 2006;14(11):11511157

9 Guzoglu N, Gokmen T, Oguz SS, Fitoz S, Dilmen U. Isolated macrodystrophia lipomatosa of the foot in a neonate: a case report. Clin Dysmorphol 2012;21(1):53-55

10 Lacombe D, Battin J. Isolated macrodactyly and Proteus syndrome. Clin Dysmorphol 1996;5(3):255-257

11 Lublin M, Schwartzentruber DJ, Lukish J, Chester C, Biesecker LG Newman KD. Principles for the surgical management of patients with Proteus syndrome and patients with overgrowth not meeting Proteus criteria. J Pediatr Surg 2002;37(7):10131020

12 Biesecker LG, Sapp JC. Proteus syndrome. In: Pagon RA, Bird TD, Dolan CR, Stephens K, Adam MP, eds. GeneReviews ${ }^{\mathrm{TM}}$ [Internet]. Seattle, WA: University of Washington; 1993. Updated August 9, 2012 